\title{
VALIDASI DAN VERIFIKASI METODE UJI FOSFAT DENGAN SPEKTROFOTOMETER UVI-VIS DI LABORATORIUM KIMIA
}

\author{
Susiana Nurmalawati ${ }^{1)}$ Charles Banon ${ }^{2),}$ Devirizanty ${ }^{3),}$ \\ Laboratorium Kimia ,Fakultas Matematika dan Ilmu Pengetahuan Alam, Universitas Bengkulu, \\ JL.Wr Supratman Kandang Limun Bengkulu 383711. \\ Laman: www.fmipa.ac.id email:fmipa-unib03@yahooo.com \\ susiana@unib.ac.id
}

\begin{abstract}
ABSTRAK
Uji Fosfat adalah salah satu parameteter uji yang diajukan dalam pengajuan akreditasi FMIPA di laboratorium kimia. Uji ini juga memiliki kelengkapan alat dan bahan yang baik sehingga pelayanan pengujian dilakukan dengan penggunaan spektrofometri yang tersedia. Sebagai salah satu parameter yang diujikan, selama ini belum dilakukan verfikasi metode uji untuk penentuan batas terendah fosfat yang dapat dideteksi oleh alat spektrofotometri, sehingga unjuk kerja dari pengujian belum diketahui, dan hasil keabsahan pengujian belum dapat dicapai. Dengan adanya kegiatan verifikasi ini, diharapkan dapat juga dikembangkan untuk penentuan validasi ataupun verfikasi pengembangan metode yang lain.Kegiatan pengujian fosafat merujuk pada metode baku SNI sehingga lagkah verifikasi diterapkan. Verifikasi menggunakan pendekatan teknik statistik yang sesuai untuk penerapannya dan relevan dengan perubahan pengujian. Uji verifikasi dan validasi memiliki paramer uji statistik yang sama, diantaranya: Simpangan deviasi, Nilai keberterimaan pengujian melalui uji Horwatz, dan penetapan presisi dan akurasinya dengan menggunakan acuan CRM (Certified Reference Material) bahan PO42-. Pada percobaan kali dihasilkan data untuk deteksi batas terendah yang dapat diukur dengan baik oleh alat spektrofotometri UV-Vis Cary 60 sebesar $0,0660 \mathrm{mg}$ P/L, dan uji presisinya memilki kebereterimaan yang baik. Kedepannya validasi dan verifikasi metode uji dapat menjadi salah satu penunjang persyaratan laboratorium kimia sebagai laboratium uji yang menerapkan ISO 17025.
\end{abstract}

Kata Kunci: Spektofotometer UV-Vis, validasi dan verifikasi metode uji

\begin{abstract}
Phosphate Test is one of the test parameters proposed in the application for FMIPA accreditation in the chemical laboratory. This test was chosen because it has good equipment and materials so that testing services can be carried out using a UV-Vis Spectrophotometer. As one of the parameters being tested, so far no verification of the test method has been carried out for determining the lowest limit of phosphate that can be detected by spectrophotometry, so that the performance of the test is not yet known, and the results of the validity of the test have not been achieved. With this verification activity, it is hoped that it can also be developed for the determination of validation or verification of the development of other methods. Phosphate testing activities refer to the standard SNI method so that verification steps are applied. Verification uses a statistical engineering approach that is appropriate for its application and relevant to test changes. Verification and validation tests have the same statistical test parameters, including: Deviation deviation, Test acceptability value through Horwatz test, and determination of precision and accuracy using CRM (Certified Reference Material) PO42-. In this experiment, the data for the detection of the lowest limit that can be measured properly by the UV-Vis Cary 60 spectrophotometer was $0.0660 \mathrm{mg} \mathrm{P} / \mathrm{L}$, and the precision test had good acceptability. In the future, validation and verification of test methods can be one of the supporting requirements for chemical laboratories as test laboratories that apply ISO 17025 .
\end{abstract}

Keywords: Spektofotometer UV-Vis, validation and verification methods 


\section{PENDAHULUAN}

Laboratorium Kimia memiliki peranan sangat penting bagi kegiatan pendidikan, penelitian, dan pengabdian masyarakat. Salah satu tugas Pranata Laboratorium Pendidikan adalah pelayanan pengujian. Standarisasi pengujian sampel sebagai salah satu bentuk pelayanan kepada masyarakat memerlukan pengakuan untuk peningkatan pengujiannya. Pengakuan akan kemampuan laboratorium dalam melakukan pengujian suatu parameter dapat dilakukan melalui rangkaian kegiatan verifikasi dan validasi suatu metode. Fosfat adalah salah satu parameteter uji yang diajukan dalam pengajuan akreditasi FMIPA di laboratorium kimia. Pengujian fosfat menggunakan metode baku SNI 06-6989-312005. Dipilihnya metode ini sebagai bahan acuan kegiatan validasi dan verifikasi, diantaranya, uji ini juga memiliki kelengkapan alat dan bahan yang baik sehingga pelayanan pengujian dilakukan dengan penggunaan spektrofometri UV-Vis Cary 60 yang tersedia. Pada Metode uji juga dilengkapi dengan penjabaran persyaratan jaminan mutu yang digunakan dan batas keberterimaan hasil pengujiannya. Pembuatan varian standar dalam metode uji ini juga menggunakan batas konsentrasi yang tidak terlalu kecil sehingga dapat mudah dilakukan dengan peralatan gelas yang terdapat dilaboratorium.

Pada Verifikasi dan validasi metode fosfat ini pendekatan teknik statistik dipakai untuk penerapannya dan pemilihannya relevan dengan perubahan pengujian. Uji verifikasi dan validasi memiliki paramer uji statistik yang sama, diantaranya: Limit Deteksi Metode , Nilai keberterimaan pengujian melalui uji Horwatz, dan penetapan presisi dan akurasinya dengan menggunakan acuan CRM (Certified Reference Material) bahan $\mathrm{PO}^{2-}$. Kedepannya validasi dan verifikasi metode uji dapat menjadi salah satu penunjang persyaratan laboratorium kimia sebagai laboratium uji yang menerapkan ISO 17025.

\section{METODE}

\section{Bahan habis pakai}

\section{Alat dan Bahan \\ Alat}

1. Spektronik UV -Vis

6. Gelas Piala

2. Neraca Analitik

7. Corong

3. Erlenmeyer

8. Pipet Volumetrik $10 \mathrm{ml}$

4. Labu ukur

9. Gelas ukur

Pipet tetes

\section{Bahan}

a. Larutan asam sulfat $\left(\mathrm{H}_{2} \mathrm{SO}_{4}\right) 5 \mathrm{~N}$

Dimasukkan secara hati-hati $70 \mathrm{ml}$ asam sulfat pekat ke dalam gelas piala yang berisi $300 \mathrm{ml}$ air suling dan diletakkan pada penangas air es. Encerkan larutan dengan air suling sampai $500 \mathrm{ml}$ dan dihomogenkan.

b. Larutan kalium antimonil tartrat.

Dilarutkan 1,3715 g kalium antimonil tartrat dengan $400 \mathrm{ml}$ air suling dalam labu ukur 500 ml. Kemudian ditambahkan air suling hingga tepat tanda tera dan dihomogenkan.

c. Larutan ammonium molibdat.

Dibuat larutan ammonium molibdat dengan melarutkan $20 \mathrm{~g}$ ammonium molibdat dalam 500 $\mathrm{ml}$ air suling dan homogenkan.

d. Larutan asam askorbat.

Dilarutkan $1,76 \mathrm{~g}$ asam askorbat dalam $100 \mathrm{ml}$ air suling.

e. Larutan campuran.

Campurkan secara berturut-turut $50 \mathrm{ml} \mathrm{H}_{2} \mathrm{SO}_{4} 5 \mathrm{~N}, 5 \mathrm{ml}$ larutan kalium antimonil tartrat, 15 $\mathrm{ml}$ larutan ammonium molibdat dan $30 \mathrm{ml}$ larutan asam askorbat

f. Kalium dihidrogen fosfat anhidrat. 


\section{Instrumentasi}

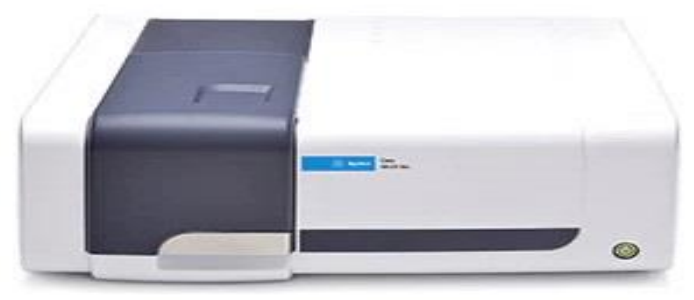

Gambar 3. Alat Spektrofotometer UV - Vis Cary 60

- Spesifikasi Alat

- Spectrophotometer UV Vis cary 60 single beam

- Produksi : Agilent Technologies

- Range Panjang gelombang190-1100 nm

- Sumber Cahaya lampu Xenon

\section{Prosedur penelitian}

1. Pembuatan Larutan Induk Fosfat $500 \mathrm{mg} / \mathrm{L}$

1. Dilarutkan 2,195 g kalium dihidrogen fosfat anhidrat/KH2PO4 dengan $100 \mathrm{ml}$ air suling dalam labu ukur $1000 \mathrm{ml}$.

2. Tambahkan air suling sampai tepat pada tanda tera dan dihomogenkan.

2. Pembuatan Larutan Baku Fosfat $10 \mathrm{mg}$ P/L

Pipet $2 \mathrm{ml}$ larutan induk fosfat $500 \mathrm{mg}$ P/L dan dimasukkan ke dalam labu ukur $100 \mathrm{ml}$, tambahkan air suling sampai tepat pada larutan tera dan dihomogenkan.

3. Pembuatan Larutan Kerja Fosfat.

1. Pipet $0 \mathrm{ml} ; 5 \mathrm{ml} ; 10 \mathrm{ml} ; 20 \mathrm{ml}$; dan $25 \mathrm{ml}$ larutan baku fosfat yang mengandung $10 \mathrm{mg} \mathrm{P} / \mathrm{L}$ dan masukkan masing-masing kedalam labu ukur $250 \mathrm{ml}$.

2. Tambahkan air suling sampai tepat tanda tera kemudian dihomogenkan sehingga kadar fosfat 0,0 mg P/L: 0,2 mg P/L: 0,4 mgP/L: 0,8 mg P/L; dan 1,0 mg P/L

4. Pembuatan Kurva kalibrasi.

1. Optimalkan alat spektrofotometer sesuai dengan petunjuk alat untuk pengujian kadar fosfat.

2. Pipet $50 \mathrm{ml}$ larutan kerja dan masukkan masing-masing kedalam erlenmeyer.

3. Tambahkan 1 tetes indikator fenolftalin. Jika terbentuk warna merah muda, tambahkan tetes demi tetes $\mathrm{H}_{2} \mathrm{SO}_{4} 5 \mathrm{~N}$ sampai watna hilang.

4. Tambahkan $8 \mathrm{ml}$ larutan campuran dan dihomogenkan.

5. Masukkan kedalam kuvet pada alat spektrofotometer baca dan catat serapan pada panjang gelombang $880 \mathrm{~nm}$ dalam kisaran waktu antara 10 menit sampai 30 menit.

6. Buat kurva kalibrasi dan tentukan persamaan garis lurusnya.

5. Jaminan mutu dan Kontrol akurasi

1. Lakukan analisis CRM untuk kontrol akurasi dalam hal digunakan $\mathrm{KH}_{2} \mathrm{PO}_{4}$ terstandar.

2. Gunakan alat gelas bebas kontaminan

3. Gunakan alat ukur terkalibrasi

4. Dikerjakan analis berkompeten

5. Lakukan analis dalam waktu yang tidak melampaui waku penyimpanan maksimum. 
Cara Kerja:

A. Penentuan Limit Deteksi Metode (Methods Detection Limit, MDL) dan Limit Quantifikasi (LoQ)

1. Dibuat larutan dengan konsentrasi $0,2 \mathrm{mg} / \mathrm{P}$ untuk penetapan limit deteksi dari bahan CRM Potasium dihidrogen phospat $\left(\mathrm{KH}_{2} \mathrm{PO}_{4}\right.$ ke dalam labu ukur $50 \mathrm{~mL}$.

2. Diukur ke sepuluh larutan tersebut pada panjang gelombang $880 \mathrm{~nm}$. Catat hasil pengukuran dan hitung konsentrasi masing-masing larutan dengan menggunakan persamaan garis lurus yang diperoleh dari kurva kalibrasi.

3. Hitung kadar rata-rata, standar deviasi, \%RSD, Signal to Noise (S/N), MDL, LoQ menggunakan Excel

4. Bandingkan hasil perhitungan dengan persyaratan yang ditentukan.

5. Penentuan Presisi dengan Repeatabilitas dan Akurasinya.

Pengujian presisi dan akurasi dengan cara mengukur sampel uji yang di tentukan pada konsentrasi rendah, sedang, dan tinggi pada daerah kerja metode pengujian. Dibuat larutan dari bahan CRM Potasium dihidrogen phospat $\left(\mathrm{KH}_{2} \mathrm{PO}_{4}\right)$ sesuai varian kadar yang ditentukan. Pembuatan variasi larutan uji adalah $0,2 \mathrm{ppm} ; 0,5 \mathrm{ppm}$; dan 0,8 ppm sebanyak 10 buah setiap varisi konsenterasi.

\section{HASIL DAN PEMBAHASAN}

Hasil pelaksanaan penelitian validasi dan verifikasi uji fosfat dengan metode SNI SNI 066989-31-2005 dari bulan Juni 2021 menghasilkan beberapa data sebagai berikut:

\begin{tabular}{ccc}
\hline No & Konsentrasi & Absorbansi \\
\hline 1 & 0 & 0,0004 \\
2 & 0,2 & 0,036 \\
3 & 0,4 & 0,0755 \\
4 & 0,6 & 0,1244 \\
5 & 0,8 & 0,141 \\
6 & 1 & 0,1958 \\
7 & 1,2 & 0,2423 \\
\hline
\end{tabular}

Tabel 1. Data deret standar Fosfat

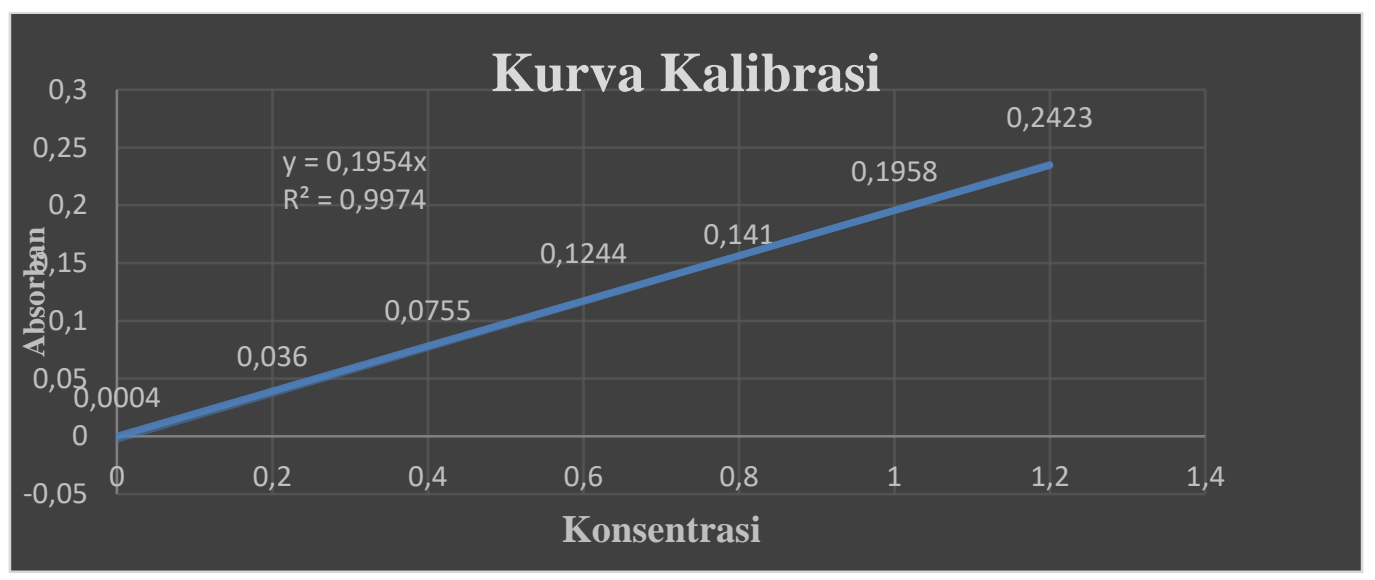

Gambar 1. Kurva regresi deret standar fosfat

Dari pembacaan grafik diatas, diperoleh persamaan $\mathrm{y}=0,1954 \mathrm{x}$ dan nilai $\mathrm{R}^{2}=0,9918$. Kesimpulannya nilai $\mathrm{R}^{2}=\geq 0.990$ sehingga memenuhi batas keberterimaan lineritas kurva. Selanjutnya dilakukan uji lineritas kurva dengan menggunakan analysis of varian, maka dihasilkan kesimpulan dibawah ini.

Tabel 2. Analisis Data Analis of varian 
SUMMARY OUTPUT

\begin{tabular}{lr}
\hline \multicolumn{2}{c}{ Regression Statistics } \\
\hline Multiple R & 0,996049746 \\
R Square & 0,992115097 \\
Adjusted R & \\
Square & 0,990538116 \\
Standard Error & 0,008369298 \\
Observations & 7 \\
\hline
\end{tabular}

ANOVA

\begin{tabular}{lrrrrr}
\hline & & & & & Significanc \\
& $D f$ & \multicolumn{1}{c}{$S S$} & \multicolumn{1}{c}{$M S$} & \multicolumn{1}{c}{$F$} & \multicolumn{1}{c}{ F } \\
\hline & & & 0,04406702 & 629,123177 & $1,87974 \mathrm{E}-$ \\
Regression & 1 & 0,044067023 & 3 & 7 & 06 \\
Residual & 5 & 0,000350226 & $7,00451 \mathrm{E}-05$ & & \\
Total & 6 & 0,044417249 & & & \\
\hline
\end{tabular}

\begin{tabular}{|c|c|c|c|c|c|c|c|}
\hline & & Standard & & & & Upper & Upper \\
\hline & Coefficients & Error & $t$ Stat & $P$-value & Lower $95 \%$ & $95 \%$ & $95,0 \%$ \\
\hline Intercept & $-0,002529$ & 0,005703 & $-0,443398$ & 0,676006 & $-0,017188$ & 0,012131 & 0,012131 \\
\hline $\begin{array}{l}\mathrm{X} \\
\text { Variable1 }\end{array}$ & 0,198357 & 0,007908 & 25,082328 & 0,000002 & 0,178028 & 0.218686 & 0.218686 \\
\hline
\end{tabular}

\begin{tabular}{|cccc|}
\hline Evaluasi & Persyaratan & Hasil & kesimpulan \\
\hline Nilai F & $\mathrm{F}<0,05$ & $1,87974 \mathrm{E}-06$ & memenuhi \\
Nilai regresi & $\mathrm{R} 2>0,995$ & 0,992115097 & memenuhi \\
intercept & $<0,19835$ & 0,012130724 & memenuhi \\
\hline
\end{tabular}

Penetapan Limit Deteksi Metode / Nilai MDL

Dilakukan penetapan nilai limit deteksi metode dengan cara pembuatan larutan dengan konsentrasi 0,2 mg P/L dari bahan $\mathrm{K}_{2} \mathrm{HPO}_{4}$ yang terstandar ( CRM ). Dihasilkan data dibawah ini.

Tabel 3. Data MDL Analis data secara statistik

\begin{tabular}{rrrrr}
\hline No & Kadar P (ppm) & y (absorbansi) & a (slope) & x (kadar P hitung) \\
\hline 1 & 0,2 & 0,0392 & 0,1954 & 0,200614125 \\
2 & 0,2 & 0,0396 & 0,1954 & 0,202661208 \\
3 & 0,2 & 0,0403 & 0,1954 & 0,206243603 \\
4 & 0,2 & 0,0406 & 0,1954 & 0,207778915 \\
5 & 0,2 & 0,0476 & 0,1954 & 0,243602866 \\
6 & 0,2 & 0,0306 & 0,1954 & 0,156601842 \\
7 & 0,2 & 0,0415 & 0,1954 & 0,212384852 \\
8 & 0,2 & 0,0441 & 0,1954 & 0,225690890 \\
9 & 0,2 & 0,0410 & 0,1954 & 0,209825998 \\
10 & 0,2 & 0,0392 & 0,1954 & 0,200614125 \\
\hline
\end{tabular}




\begin{tabular}{|c|c|c|c|}
\hline \multirow{2}{*}{ No } & \multicolumn{2}{|c|}{ Kadar (mg/L) } & \multirow{2}{*}{$\% \mathrm{R}$} \\
\hline & Pembacaan & Perhitungan & \\
\hline 1 & 0,2 & 0,2006141 & 100,31 \\
\hline 2 & 0,2 & 0,2026612 & 101,33 \\
\hline 3 & 0,2 & 0,2062436 & 103,12 \\
\hline 4 & 0,2 & 0,2077789 & 103,89 \\
\hline 5 & 0,2 & 0,2436029 & 121,80 \\
\hline 6 & 0,2 & 0,15666018 & 78,33 \\
\hline 7 & 0,2 & 0,2123849 & 106,19 \\
\hline 8 & 0,2 & 0,2256909 & 112,85 \\
\hline 9 & 0,2 & 0,209826 & 104,91 \\
\hline 10 & 0,2 & 0,2006141 & 100,31 \\
\hline \multicolumn{2}{|c|}{$\operatorname{Rerata}(\mathrm{x})$} & 0,2066 & 103,30 \\
\hline \multicolumn{2}{|l|}{$\mathrm{Sd}$} & \multicolumn{2}{|l|}{0,0220} \\
\hline \multicolumn{2}{|c|}{$\% \mathrm{RSD}=(\mathrm{sd} / \mathrm{X})$} & \multicolumn{2}{|l|}{10,6534} \\
\hline \multicolumn{2}{|c|}{$\mathrm{S} / \mathrm{N}=\mathrm{x} / \mathrm{sd}$} & \multicolumn{2}{|l|}{9,3867} \\
\hline \multicolumn{2}{|c|}{$\mathrm{MDL}=3 \mathrm{sd}$} & \multicolumn{2}{|l|}{0,0660} \\
\hline \multicolumn{2}{|c|}{$\mathrm{LoQ}=10 \mathrm{sd}$} & \multicolumn{2}{|l|}{0,2201} \\
\hline
\end{tabular}

Evaluasi hasil

Tabel 4. Perhitungandan MDL

\begin{tabular}{|c|l|c|c|}
\hline \multicolumn{1}{|l|}{ No } & \multicolumn{1}{|c|}{ Persyaratan } & Hasil & Kesimpulan \\
\hline 1 & $\% \mathrm{RSD}=15,16$ & 10,65 & Memenuhi \\
\hline 2 & $\% \mathrm{R}=75 \%-120 \%$ & 100,36 & Memenuhi \\
\hline 3 & $\mathrm{~s} / \mathrm{N}=2,5-10$ & 9,39 & Memenuhi \\
\hline 4 & MDL $<$ Kadar spike & $0,0692<0,2$ & Memenuhi \\
\hline 5 & Kadar spike < 10 MDL & $0,2<0,692$ & Memenuhi \\
\hline 6 & MDL < BML & $0,0692<0,2$ & Memenuhi \\
\hline 7 & \multicolumn{2}{|c|}{ jika MDL diterima, maka LoQ $=10$ sd diterima } \\
\hline
\end{tabular}

Pada Penetapan Limit Deteksi Metode ini adalah penetapan batas konsentrasi terkecil dari fosfat yang dapat diukur oleh Spektrofotometer UV-Vis Cary 60. Dan dari hasil didapatkan bahwa batas konsetrasi P terkecil adalah 0,0687. Dari tabel juga terlihat bahwa pengukuran MDL ini memiliki rentang sinyal kesalahan sebesar 9,38\%. Kesalahan ini harus ditelusuri kembali karena faktor khusunya kesalahan acak yaitu kesalahan alat gelas yang digunakan, kesalahan ketrampilan uji, dan kesalahan instrumen dari segi kalibrasinya yang belum dilakukan kalibrasi karena kurangnya sumberdaya kompetensi instrumen analitik, dan ketersediaan peralatan gelas yang memenuhi standar untuk pengujian. Jika dilihat dari usia instrumen, spektrofotometer ini masih termasuk kategori baru, yaitu Instrumen analitik yang bersal dari Dana APBN Tahun 2012, sehingga tidak menutup kemungkinan risiko kesalahan dari faktor ini sangat sedikit.

\section{Penetapan Presisi}

Dilakukan uji presisi dengan cara pembuatan larutan dari bahan $\mathrm{K}_{2} \mathrm{HPO}_{4}$ yang terstandar ( CRM) pada konsentrasi rendah $=0,2 \mathrm{ppm}$; sedang $=0,5 \mathrm{ppm}$ : dan tinggi $=0,8 \mathrm{ppm}$.

Tabel 5. Perhitungandan Presisi kadar $\mathrm{P}=0,2 \mathrm{ppm}$ 
Analisis Data Presisi kadar $\mathrm{P}=0,2 \mathrm{ppm}$

\begin{tabular}{|c|c|c|c|c|}
\hline \multirow{2}{*}{ No } & \multicolumn{2}{|c|}{ Kadar (mg/L) } & \multirow{2}{*}{$\% R(75-120)$} & \multirow{2}{*}{ Kesimpulan } \\
\hline & Pembacaan & Perhitungan & & \\
\hline 1 & 0,2 & 0,200614125 & 100,3071 & Diterima \\
\hline 2 & 0,2 & 0,202661208 & 101,3306 & Diterima \\
\hline 3 & 0,2 & 0,206243603 & 103,1218 & Diterima \\
\hline 4 & 0,2 & 0,207778915 & 103,8895 & Diterima \\
\hline 5 & 0,2 & 0,243602866 & 121,8014 & Diterima \\
\hline 6 & 0,2 & 0,156601842 & 78,3009 & Diterima \\
\hline 7 & 0,2 & 0,212384852 & 106,1924 & Diterima \\
\hline 8 & 0,2 & 0,22569089 & 112,8454 & Diterima \\
\hline 9 & 0,2 & 0,209825998 & 104,9130 & Diterima \\
\hline \multirow[t]{6}{*}{10} & 0,2 & 0,200614125 & 100,3071 & Diterima \\
\hline & $\operatorname{Rerata}(\mathrm{x})$ & 0,20660 & \multirow[t]{4}{*}{103,3009} & \multirow[t]{4}{*}{ Diterima } \\
\hline & Standar deviasi (sd) & 0,02203 & & \\
\hline & $\% \mathrm{RSD}=(\mathrm{sd} / \mathrm{X})$ & 10,66078 & & \\
\hline & 0.67 CVhorwitz & 13,5918 & & \\
\hline & $\%$ RSD<0.67 CVhorwitz & & \multicolumn{2}{|c|}{ Diterima } \\
\hline
\end{tabular}

\begin{tabular}{|c|c|c|c|r|}
\hline $\mathrm{C}$ & $\log \mathrm{C}$ & $1-0,5 \log \mathrm{C}$ & $2^{1-0.5 \log \mathrm{C}}$ & HorRat Value \\
\hline 0,2066 & $-6,6849$ & 4,3424 & 20,2863 & 0,52552 \\
\hline
\end{tabular}

Tabel 6. Perhitungandan Presisi kadar $\mathrm{P}=\mathrm{P}=0,5 \mathrm{ppm}$

Presisi Kadar $\mathbf{P}=0,5$ ppm

Presisi Kadar $\mathbf{P}=0,5$ ppm

\begin{tabular}{rcccr}
\hline No & Kadar P $(\mathrm{ppm})$ & $\mathrm{y}$ (absorbansi) & a (slope) & x (kadar P hitung) \\
\hline 1 & 0,5 & 0,1005 & 0,1954 & 0,514329580 \\
2 & 0,5 & 0,1018 & 0,1954 & 0,520982600 \\
3 & 0,5 & 0,1041 & 0,1954 & 0,532753327 \\
4 & 0,5 & 0,1043 & 0,1954 & 0,533776868 \\
5 & 0,5 & 0,1047 & 0,1954 & 0,535823951 \\
6 & 0,5 & 0,1042 & 0,1954 & 0,533265097 \\
7 & 0,5 & 0,1045 & 0,1954 & 0,534800409 \\
8 & 0,5 & 0,1053 & 0,1954 & 0,538894575 \\
9 & 0,5 & 0,1051 & 0,1954 & 0,537871034 \\
10 & 0,5 & 0,1048 & 0,1954 & 0,536335722 \\
\hline
\end{tabular}

Analisis secara statistik

\begin{tabular}{|c|c|c|c|}
\hline \multicolumn{2}{|c|}{ Kadar $(\mathbf{m g} / \mathbf{L})$} & \multirow{2}{*}{$\% \mathbf{R}(\mathbf{8 0 - 1 1 5})$} & \multirow{2}{*}{ Kesimpulan } \\
\cline { 1 - 2 } Pembacaan & Perhitungan & & \\
\hline 0,5 & 0,51432958 & 102,86592 & Diterima \\
\hline 0,5 & 0,5209826 & 104,19652 & Diterima \\
\hline 0,5 & 0,532753323 & 106,55066 & Diterima \\
\hline 0,5 & 0,533776868 & 106,75537 & Diterima \\
\hline 0,5 & 0,535823951 & 107,16479 & Diterima \\
\hline
\end{tabular}




\begin{tabular}{|c|c|c|c|}
\hline 0,5 & 0,533265097 & 106,65302 & Diterima \\
\hline 0,5 & 0,534800409 & 106,96008 & Diterima \\
\hline 0,5 & 0,538894575 & 107,77892 & Diterima \\
\hline 0,5 & 0,537871034 & 107,57421 & Diterima \\
\hline 0,5 & 0,536335722 & 107,26714 & Diterima \\
\hline $\operatorname{Rerata}(\mathrm{x})$ & 0,53188 & 106,3767 & Diterima \\
\hline Standar deviasi (sd) & 0,00790 & & \\
\hline$\% \mathrm{RSD}=(\mathrm{sd} / \mathrm{X})$ & 1,48581 & & \\
\hline 0.67 CVhorwitz & 11,7886 & & \\
\hline$\% \mathrm{RSD}<0.67$ CVhorwitz & & \multicolumn{2}{|c|}{ Diterima } \\
\hline
\end{tabular}

\begin{tabular}{|c|c|c|c|r|}
\hline $\mathrm{C}$ & $\log \mathrm{C}$ & $1-0,5 \log \mathrm{C}$ & $2^{1-0.5 \log \mathrm{C}}$ & HorRat Value \\
\hline 0,5319 & $-6,2742$ & 4,1371 & 17,5950 & 0,08445 \\
\hline
\end{tabular}

Tabel 7. Perhitungandan Presisi kadar $\mathrm{P}=\mathrm{P}=0,8 \mathrm{ppm}$

Presisi Kadar $\mathbf{P}=\mathbf{0 , 8} \mathbf{~ p p m}$

\begin{tabular}{rcccr}
\hline \multicolumn{1}{l}{ No } & Kadar P (ppm) & y (absorbansi) & a (slope) & x (kadar P hitung) \\
\hline 1 & 0,8 & 0,1615 & 0,1954 & 0,826509724 \\
2 & 0,8 & 0,1469 & 0,1954 & 0,751791198 \\
3 & 0,8 & 0,1598 & 0,1954 & 0,817809621 \\
4 & 0,8 & 0,1619 & 0,1954 & 0,828556807 \\
5 & 0,8 & 0,1611 & 0,1954 & 0,824462641 \\
6 & 0,8 & 0,1617 & 0,1954 & 0,827533265 \\
7 & 0,8 & 0,1617 & 0,1954 & 0,827533265 \\
8 & 0,8 & 0,1622 & 0,1954 & 0,830092119 \\
9 & 0,8 & 0,1620 & 0,1954 & 0,829068577 \\
10 & 0,8 & 0,1616 & 0,1954 & 0,827021494 \\
\hline
\end{tabular}

Analisis secara statistik

\begin{tabular}{|c|c|c|c|}
\hline \multicolumn{2}{|c|}{ Kadar (mg/L) } & \multirow{2}{*}{$\%$ R (80-115) } & \multirow{2}{*}{ Kesimpulan } \\
\hline Pembacaan & Perhitungan & & \\
\hline 0,8 & 0,826509724 & 103,3137155 & Diterima \\
\hline 0,8 & 0,751791198 & 93,97389975 & Diterima \\
\hline 0,8 & 0,817809621 & 102,2262026 & Diterima \\
\hline 0,8 & 0,828556807 & 103,5696009 & Diterima \\
\hline 0,8 & 0,824462641 & 103,0578301 & Diterima \\
\hline 0,8 & 0,827533265 & 103,4416581 & Diterima \\
\hline 0,8 & 0,827533265 & 103,4416581 & Diterima \\
\hline 0,8 & 0,830092119 & 103,7615149 & Diterima \\
\hline 0,8 & 0,829068577 & 103,6335721 & Diterima \\
\hline 0,8 & 0,827021494 & 103,3776868 & Diterima \\
\hline $\operatorname{Rerata}(\mathrm{x})$ & 0,81904 & 102,3797 & Diterima \\
\hline Standar deviasi (sd) & 0,02388 & & \\
\hline$\% \mathrm{RSD}=(\mathrm{sd} / \mathrm{X})$ & 2,91507 & & \\
\hline 0.67 CVhorwitz & 11,0470 & & \\
\hline
\end{tabular}




\begin{tabular}{|l|l|} 
& Diterima \\
\hline
\end{tabular}

\begin{tabular}{|c|c|c|c|l|}
\hline $\mathrm{C}$ & $\log \mathrm{C}$ & $\begin{array}{c}1-0,5 \log \\
\mathrm{C}\end{array}$ & $2^{1-0.5 \log \mathrm{C}}$ & $\begin{array}{l}\text { HorRat } \\
\text { Value }\end{array}$ \\
\hline 0,8190 & $-6,0867$ & 4,0433 & 16,4880 & 0,17680 \\
\hline
\end{tabular}

\section{KESIMPULAN}

Kesimpulan berisikan tentang ringkasan hasil penelitian, tanpa tambahan interpretasi baru lagi dan dapat juga dituliskan kelebihan dan kekurangan dari penelitian, serta rekomendasi untuk penelitian selanjutnya.

\section{DAFTAR PUSTAKA}

Abdul Rohman.(2016).Validasi dan Penjaminan Mutu Metoda Analisis Kimia. Yogyakarta : Penerbit Gadjah Mada University Press.

Anwar Hadi.(2018).Persyaratan Umum Kompetensi Laboratorium Pengujian \& Laboratorium Kalibrasi.Jakarta : Penerbit PT Gramedia Pustaka Utama.

Anom Irawan. Kalibrasi Spektrofotometer Sebagai Penjaminan Mutu Hasil Pengukuran Dalam Kegiatan Penelitian Dan Pengujian.Indonesian Journal of Laboratory.2019, Volume 1, Hal. 19

Ardhaningtyas Riza Utami. Verifikasi Metode sulfat Dalam Air dan Air Limbah sesuai SNI 6989 .20 :2019. Jurnal Teknologi Proses dan Inovasi Industri.2017, Volume 2, Hal. 1 - 7

Astari Simbolon Monica Magdalena, Aman Sentosa Panggabean, Moh.Syaiful Arif. Validasi Penentuan Cadmium(Cd) pada Pupuk Organik Menggunakan Spektrofotometer Serapan Atom (SSA) di PT.Global Environment Laboratory Prosiding Seminar Nasional Kimia Lingkungan.2020.

Eurachem, The Fitness For Purpose of Analytical Methods, $2^{\text {nd }}$ ed, 2014

Hendayana Sumar.(2006).Buku Materi Instrumen Analitik . Jakarta.Penerbit Universitas Terbuka.

SNI 06-6989-31-2005 Air dan Limbah : Cara Uji Fosfat secara S0ektrofotometri. Badan Standard Nasional.

Riyanto.(2014).Validasi danVerifikasi Metode Uji. Laboratorium Pengujian dan Kalibrasi.Yogyakarta. Penerbit deepublish.

Validasi danVerifikasi Metode Uji. Laboratorium Pengujian dan Kalibrasi.Yogyakarta. Penerbit deepublish. 